\title{
Selection of conductive yarns for knitting an electrical heating element
}

\author{
I. Šahta ${ }^{1}$, I. Baltina ${ }^{1}$, N. Truskovska ${ }^{1}$, J. Blums $^{2}$ \& E. Deksnis ${ }^{3}$ \\ ${ }^{I}$ Institute of Textile Materials Technologies and Design, \\ Riga Technical University, Latvia \\ ${ }^{2}$ Institute of Technical Physics, Riga Technical University, Latvia \\ ${ }^{3}$ Faculty of Electronics and Telecommunications, \\ Riga Technical University, Latvia
}

\begin{abstract}
By the integration of electro-conductive properties in the fabric structure a flexible textile can be obtained that does not reduce the quality of comfort, maintenance and wearability of clothing. Each type of yarn has its advantages and disadvantages, for example, metal coated polymer multifilament yarn has a lower resistance to heat than metal multifilament yarn, but it is more flexible. During this research conductive knitted patterns were made and tested. For the experiments more suitable yarns for knitting were selected, which had a lower resistance and were visually less changing of the knitted pattern in appearance: silver coated multifilament polyamide, products of two different companies; stainless steel multifilament yarn and polyester/stainless steel spun yarn. The single-faced patterns of non-conductive yarn and straight and figural conductive traces of conductive yarns were knitted. A test was made with the purpose of finding out the electrical resistance of knitted textile affected by force. Knit warm-up potency was researched during temperature measurement tests. Knitting test pieces were also evaluated by aspect of technical structure and visual appearance. Generally, it was concluded that steel yarns could not be used for knitting while silver coated polyamide yarns are suitable for the manufacture of knitted heating elements. As a result of this research, knitwear with a textile heating element was made.

Keywords: electrically conductive yarn, electrical resistance, resistive heating element, knitted heating element.
\end{abstract}




\section{Introduction}

During the cool seasons people have a need to keep their body heat for comfort. This problem could be solved by wearing clothing with an additional warming function and mostly it is knitwear. However, it is not always possible to achieve an optimal human microclimate with traditional knitwear. Similarly, the use of additional heating of a resistive textile heating element could help people who have problems with constantly cold hands or who need to stay in cool conditions indoors for a long time. There are several studies where it is confirmed that capacity for work declines rapidly in a cool environment, including working at the computer. This is due to the slowing of blood flow in the hands. Hand cooling is already observed in room temperatures of $20^{\circ} \mathrm{C}-22^{\circ} \mathrm{C}$ for seated employees; however, work efficiency at $18^{\circ} \mathrm{C}$ decreases by 5 to $15 \%$ compared with the optimal indoor microclimate of $24^{\circ} \mathrm{C}$ [1]. Depending on the ambient temperature, the hand temperature on the skin surface reaches an average of $22^{\circ} \mathrm{C}$ (in a cold environment) to $37^{\circ} \mathrm{C}$ (in a hot environment) [2].

In recent years, the integration of various electronic components and devices into textiles to give additional functions have become more common. The integration of electrically conductive elements can be achieved through various textile technologies: sewing, weaving or printing, as well as knitting [3].

Electrically conductive knitted textiles should maximally maintain the properties of traditional knitwear and should provide the feeling of comfort to the wearer. The textile product must be air permeable, offer ease of movement and keep its form whilst being worn. It should also be considered that the electric heating textile has to be regarded as an electrical device and it is important to lay down certain safety factors such as: the maximum surface temperature must not be hazardous for the human body; to avoid wearing the heating element in direct contact with the skin; the product should be washable; it is necessary also to provide electrical insulation, etc. [4].

The aim of this research is to find criteria for the selection of appropriate electrically conductive yarns for the knitting of resistive textile heating element both by their electrical properties, as well as suitability for the integration into textile structure.

\section{Materials characterisation}

\subsection{Conductive yarns}

Fabric coatings containing metal particles, as well as conductive inks during the applying process partly are integrated into the fabric structure. However, the electrical properties are often unstable or tend to be lost whilst being worn; for example, stretching can result in a loss of contact between the metal particles [5]. Although the conductive yarns are suitable for integration into textiles without limiting the textile properties, it should be noted that such yarns tend to have a higher electrical resistance than metal wires [6]. Therefore, the currently 
commercially available conductive yarns are more suitable for electrical systems with low power use.

Generally for research and for the integration into smart textiles, different types of conductive yarns are used: non-metallic carbon fibre yarns; yarn constructions with staple or filament length metal fibres; yarn constructions with staple or filament length metal fibres combined with non-metallic fibres (polyamide, polyester, etc.); yarns coated with conductive polymers or metals and synthetic fibers filled with carbon or metal particles. To improve conductive yarn performance, they may be additionally processed; for example, coated with insulating material.

Within this research there are experimentally compared stainless steel multifilament yarns which have a constant conductivity even with mechanical load variation and can withstand very high temperatures (up to $600^{\circ} \mathrm{C}$ ) [7], silver coated polyamide multifilament yarns, which are suitable for different textile technologies; they are flexible and have a good electrical and thermal conductivity (products of two manufacturers) [8,9], as well as polyester and stainless steel fibre spun yarn. The characteristics of the yarns are given in table 1 .

Table 1: Characteristics of conductive yarns used for experiments.

\begin{tabular}{|c|c|c|c|c|}
\hline No & Type of yarn & $\begin{array}{l}\text { Linear density } \\
\text { (tex), basic yarn }\end{array}$ & Yarn structure & $\begin{array}{l}\text { Additional } \\
\text { processing }\end{array}$ \\
\hline & Stainless steel & & & \\
\hline 1. & THERMOTECH N-14 & 500 & multifilament & PTFE impregnated \\
\hline \multirow[t]{2}{*}{2.} & TERMOTECH N-30 & 240 & $\begin{array}{l}\text { 2-ply twisted, } \\
\text { multifilament }\end{array}$ & - \\
\hline & Silver coated polyamide & & & \\
\hline 4. & ELITEX HE 234/f34 & 23,0 & 34 filaments & elastic yarn core \\
\hline 5. & ELITEX 110/f 34 & 11,0 & 34 filaments & - \\
\hline 6. & ELITEX 110/f 34x 2 & 11,0 & $\begin{array}{l}34 \text { filaments, } \\
\text { 2-ply twisted }\end{array}$ & - \\
\hline \multirow[t]{2}{*}{8.} & SHIELDEX 235/f34 x4 & 23,5 & $\begin{array}{l}34 \text { filaments, } \\
\text { 4-ply twisted, }\end{array}$ & - \\
\hline & $\begin{array}{l}80 \% \text { polyester }+20 \% \\
\text { stainless steel (fibers) }\end{array}$ & & & \\
\hline 9. & $\mathrm{Nm} 10 / 3$ & 33,3 & 3-ply spun yarn & - \\
\hline
\end{tabular}

\subsection{Knitted heating elements}

The heating elements created of wires are not sufficiently flexible to effectively be applied for clothing or medical devices [10]. However, the conductive yarns provide a necessary durability, flexibility and washing of knitwear [11].

Conductive textiles could be manufactured both by traditional and innovative knitting technologies. Wires and yarns with low flexibility can be attached to the basic knitwear without knitting into the fabric structure; by attaching during 
the knitting process; by combining knitting and attaching $[12,13]$; as well as by the integration of yarns into the space of a 3-dimensional knitting structure.

Knitted structures where the heat is generated by current flow mostly consist of various zones knitted of yarns with different resistances: yarns with good electrical isolation such as polyamide; of conductive yarns with electrical resistance for heating such as silver-coated polyamide yarn; for the current conduction zones yarns with an even resistance may be used, such as stainless steel filament yarns [4].

There are many possible forms of knitted resistive heating elements areas. It should be taken into account that the total amount of electrically conductive yarn rows and columns affects the physical parameters of the heating element. A knitted basic element - loop - is created by knitting three parallel loop rows. Each loop creates a stage of electrical circuit with a definite resistance of each loop element - the head and legs of the loop - where the yarn intersection points could be considered as resistance points of electrical circuit contacts and the intervals between them - resistors. However, the loop contact mechanism and analysis of processes is quite complicated and not completely explained [14, 15]. In general, it can be considered that several knit rows form a resistor network [16].

For the experiments two types of fabric patterns are knitted:

1) The pattern for determination of resistance changes during the fabric elongation test (Fig. 1) where for the basic knitting an insulating yarn is used ( $75 \%$ wool $/ 25 \%$ polyamide) while the electrical area consists of $1 \mathrm{~m}$ long conductive thread knitted in three loop rows all being the width of the test piece. The dimensions of pattern for tests $-75 \mathrm{x}$ $85 \mathrm{~mm}$.

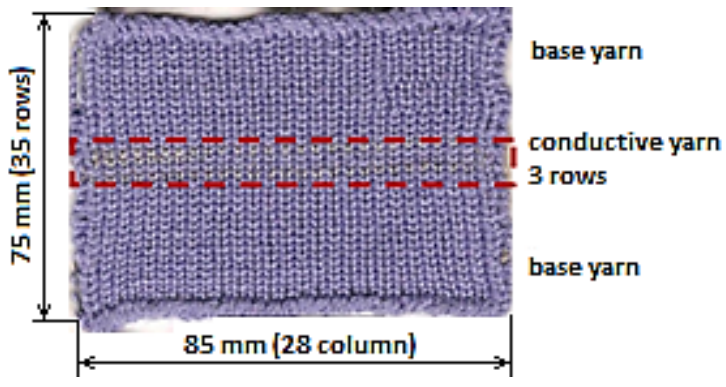

Figure 1: The knitted test piece for determination of resistance changes during the fabric elongation test.

2) The pattern with a figural conductive zone (for connecting the power source) knitted for temperature measurements during the current flow. The width of knitted resistive heating element is $\sim 75 \mathrm{~mm}$ (Fig. 2). 


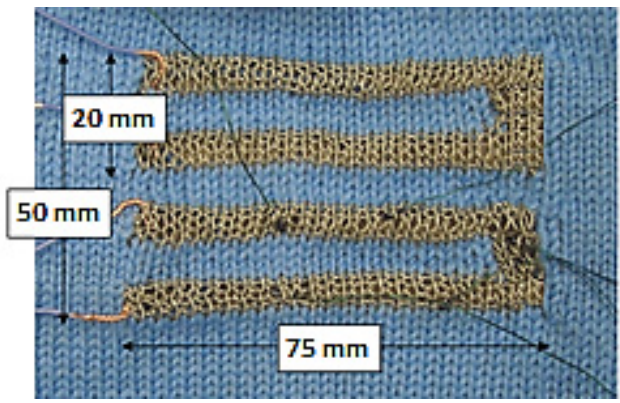

Figure 2: The knitted sample for temperature measurement tests.

\section{Experiments}

The following experiments to manufacture the knitted heating element are planned:

- Determination of resistance changes during the fabric elongation under the load;

- Temperature measurements during current flow in several points of the heating element to determine homogeneity of emitted temperature;

- Temperature measurements during the current flow of a figurative knitted pattern;

- Cyclic warm-up and cooling experiments to determine how the maximum achievable temperature of the heating element during heating processes changes.

\subsection{Determination of resistance changes during the elongation of the knitted heating element}

When the current is flowing through the resistive elements of the electric circuit the energy is released as heat. The current flowing through the element at constant voltage is dependent on the resistivity of the element. Consequently, the yarns with variable resistance during fabric elongation are not suitable for the manufacture of heating elements because of possible changes of other physical parameters.

To establish the resistance changes under the load, the conductive yarns are integrated by knitting into fabric and the elongation test is carried out (Fig. 3). The object of this test is to find out how the electrical resistance of yarns knitted in the fabric test piece changes by gradually increasing the load. The resistance $(\Omega)$ is measured before and during the increasing of load of $100 \mathrm{~g}$ up to $1000 \mathrm{~g}$.

Resistance changes under the load are not unequivocal (Fig. 4). The measurement results at the beginning show a rapidly increase of resistance by the knitted sample of polyester and conductive zone of stainless steel filament yarns under the load (to $120 \Omega$ ), and at $200 \mathrm{~g}$ and over it is significantly reduced. Similarly, it is by the sample of silver coated polyamide yarn SCHIELDEX 


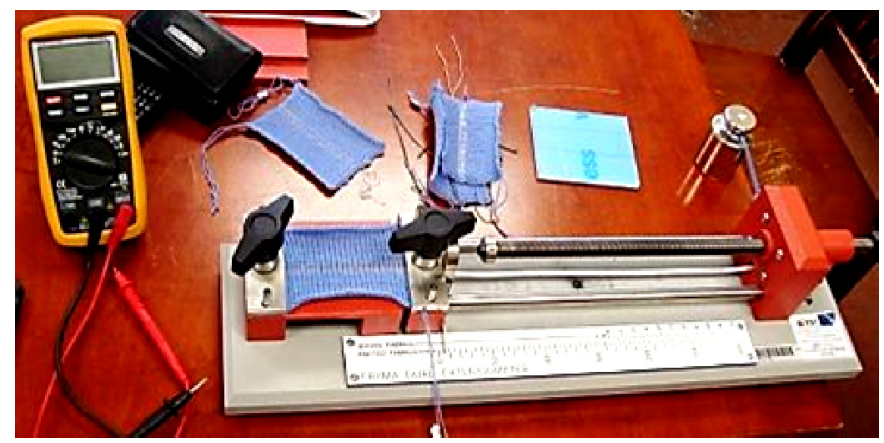

Figure 3: Knitted sample testing on the Fryma Dual Extesiometer.

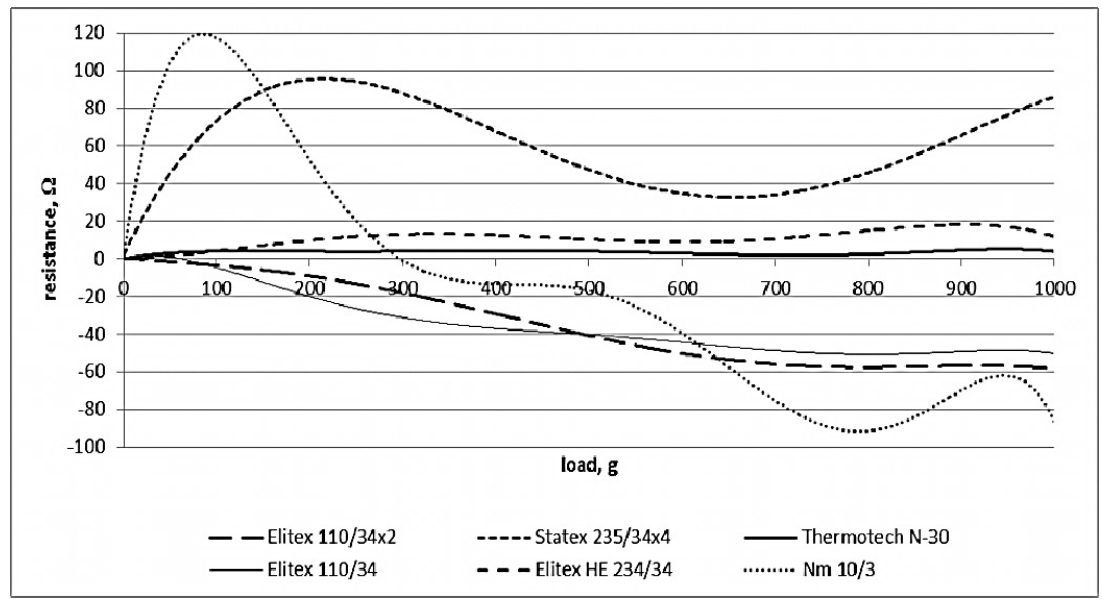

Figure 4: Resistance changes of knitted conductive fabric during tension.

235/f34x 4 where electrical resistance increases by $\sim 100 \Omega$ and the changes are uneven. The lower relative resistance changes are observed for the knitted sample with silver coated polyamide yarn - ELITEX 110dtex/f34x2 and ELITEX 110dtex/f34, but the lowest changes are observed for the samples with steel multifilament yarn THERMOTECH N-30 - 4\%, as well as for ELITEX HE $234 / 34$ silver coated polyamide with elastic yarn core $(+11 \%)$.

For the manufacturing of a knitted heating element, the spun yarn with steel fibres has to be considered as unsuitable owing to significant resistance changes of the resistive area affected by the fabric tension (to $\sim 100 \Omega$ ). Similarly, the multifilament stainless steel yarn THERMOTECH N-14 is also unsuitable for knitting since it is not sufficiently flexible; it complicates the process of knitting and deforms the knitted structure. 
The electrical resistance of conductive yarn knitted into fabric changes considerably in comparison with the resistance of unknitted yarn of the same length (Tab. 2): the resistance of $1 \mathrm{~m}$ long yarn decreases even several times compared with the $1 \mathrm{~m}$ long yarn knitted in the $1.5 \times 8.5 \mathrm{~cm}$ large area (three rows).

Table 2: $\quad$ The resistance changes of conductive yarn knitted into the fabric.

\begin{tabular}{|l|c|c|}
\hline \multicolumn{1}{|c|}{ Type of yarn } & $\begin{array}{c}\text { Resistance of } \mathbf{1 ~ m} \\
\text { long yarn }(\mathbf{\Omega})\end{array}$ & $\begin{array}{c}\text { Resistance of } \mathbf{1 ~ m} \\
\text { long knitted yarn }(\mathbf{\Omega})\end{array}$ \\
\hline ELITEX 110dtex/f 34x 2 & 40,7 & 10,5 \\
\hline ELITEX HE 234dtex/f34 & 26,9 & 3,2 \\
\hline SHIELDEX 235dtex/f34 x4 & 40,3 & 1,5 \\
\hline ELITEX 110dtex/f 34 & 34,1 & 2,1 \\
\hline THERMOTECH N-30 & 28,0 & 2,5 \\
\hline
\end{tabular}

Most changes of resistance are observed for silver coated polyamide yarn SHIELDEX 235dtex/f34x4 while the least changes are shown for silver coated polyamide yarn ELITEX $110 \mathrm{dtex} / \mathrm{f} 34 \mathrm{x} 2$, which, for that reason could be more suitable for the manufacture of a knitted heating element.

\subsection{The temperature measurements during current flow}

The object of the experiment is to observe the warm-up kinetics of the selected yarns and homogeneity and to evaluate the visual appearance of knitting and the ease of technical performance. For the experiments on each knitting test piece, the surfaces for temperature measurement are 3 thermistors and a power source with a constant voltage of $3.95 \mathrm{~V}$ attached (Fig. 5).

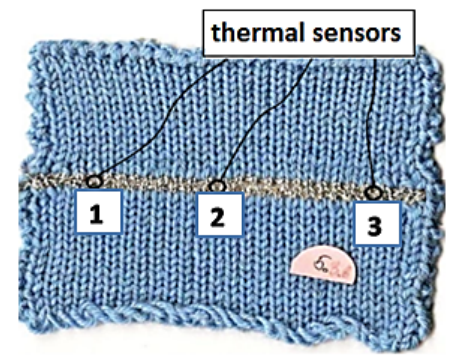

Figure 5: The knitted sample for temperature measurements during current flow.

Depending on the yarn resistance, a different amount of power is released on each knitting sample. The samples with small released power warm-up more slowly and at the definite moment the rising of temperature comes to a standstill, while the samples with established higher power warm-up quickly and could 
continue warming-up when the voltage is increased. The resistive element dissipates all the power by heat. Therefore, the warm-up temperature and warmup time can be adjusted by the selection of appropriate voltage to each yarn. For this reason, the visual appearance and ease of technical performance as well as smoothness of heating and giving out warmth becomes the most important selection criteria of yarns.

The following knitted samples with silver coated polyamide yarns are selected according to criteria of visual appearance and ease of technical performance:

- $\quad$ ELITEX 110dtex/f34x2-ply (in knitting use three-ply);

- $\quad$ ELITEX HE 234dtex/f34 (with elastic yarn core);

- $\quad$ ELITEX 110dtex/f34 (in knitting use three-ply);

- $\quad$ STATEX 235dtex/f34x4-ply.

Yarns are compared by the warm-up temperature and its evenness, as well as by the duration of warm-up (Fig. 6).

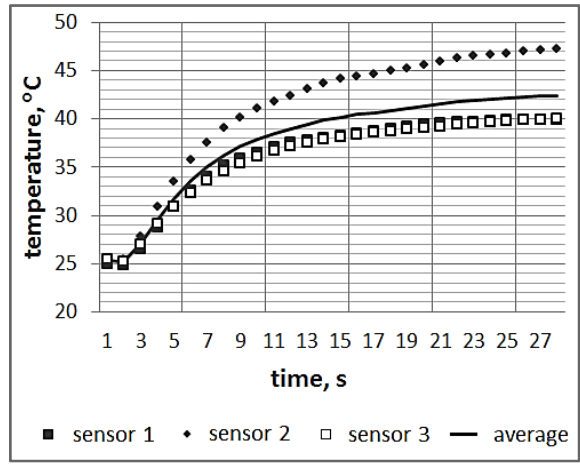

a)

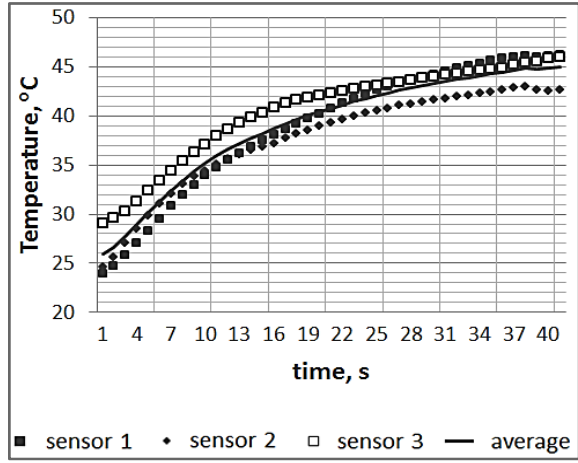

c)

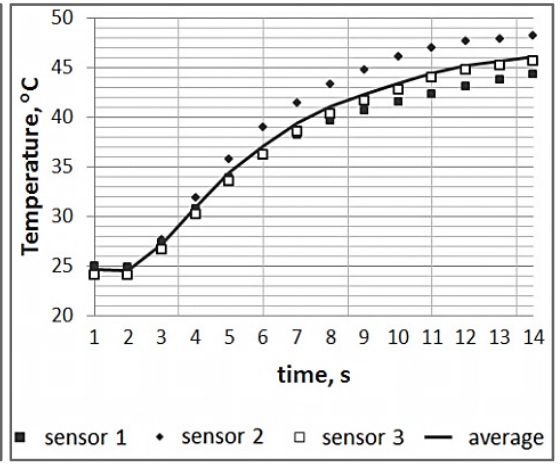

b)

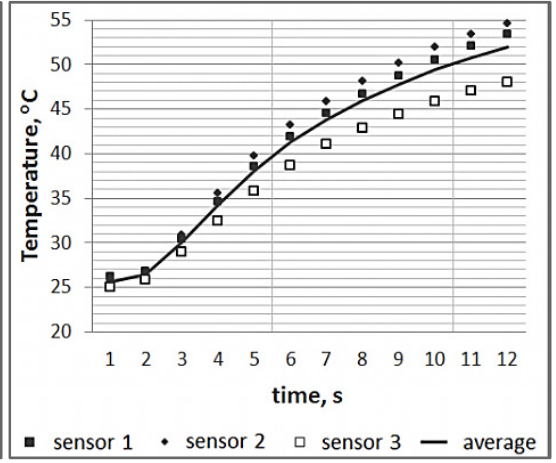

d)

Figure 6: The temperature measurement during current flow results for knitted samples of conductive yarns: a) ELITEX 110dtex/f34x2ply; b) ELITEX 110dtex/f34; c) ELITEX HE 234dtex/f34; d) SHIELDEX 235dtex/f34x4-ply. 
During this experiment it was found that the following yarns give out warmth more evenly on all the resistive areas: ELITEX HE 234/34 and SHIELDEX 235/34x4-ply, the fastest heat is released by the sample with SHIELDEX 235/34x4-ply yarn. The experiment results also show the difference in temperature between the edges and the middle of the heating element and the most distinctive results are observed by the sample with ELITEX 110dtex/f34x2ply yarn.

\subsection{Temperature measurements during the current flow through the figurative knitted heating element}

The aim of experiment is to find the warm-up temperature and its evenness for a figurative heating element of knitted conductive yarn at a constant voltage. For the experiment, single faced knitting patterns with a figural resistive heating element knitted of conductive yarns are used; 5 thermistors and a power source with a constant voltage of $1.75 \mathrm{~V}$ are attached to the sample (Fig. 7).

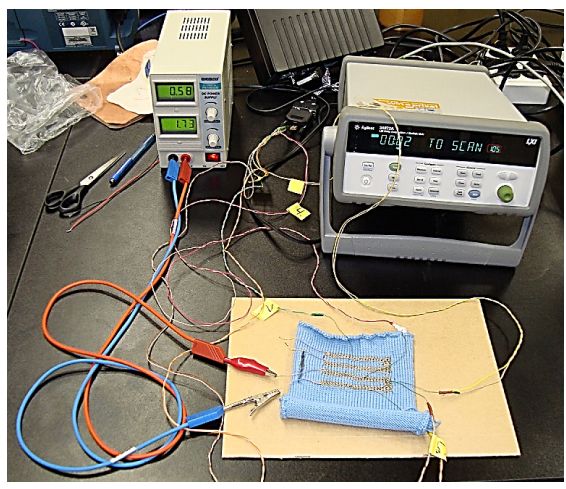

Figure 7: The equipment for temperature measurements of a figurative knitted heating element.

Experiment results with temperature values of two repeated measurements are shown in graphs (Fig. 8). Each heating zone of two zones is heated and measured separately. By analysing the results it is observed that each type of yarn has its maximum achievable temperature which is released at a constant voltage. The graphs show that the temperature rises and by achieving the maximum values it balances itself.

With a 3-ply ELITEX yarn knitted zone the warm-up time and temperature in both tests are quite similar which cannot be said about the other two types of yarn. Different results are observed in the two tests with ELITEX HE 234/34 + with elastic core yarn. By the temperature measurement of the sample with knitted SHIELDEX 235dtex/f34x4-ply yarn, the warm-up time is hesitant; the temperature rises quite uneven.

As a result of these experiments, the 3-ply silver coated ELITEX 110dtex/f34 $\mathrm{x}$ 2-ply yarn is considered as the most suitable for the manufacture of a resistive 

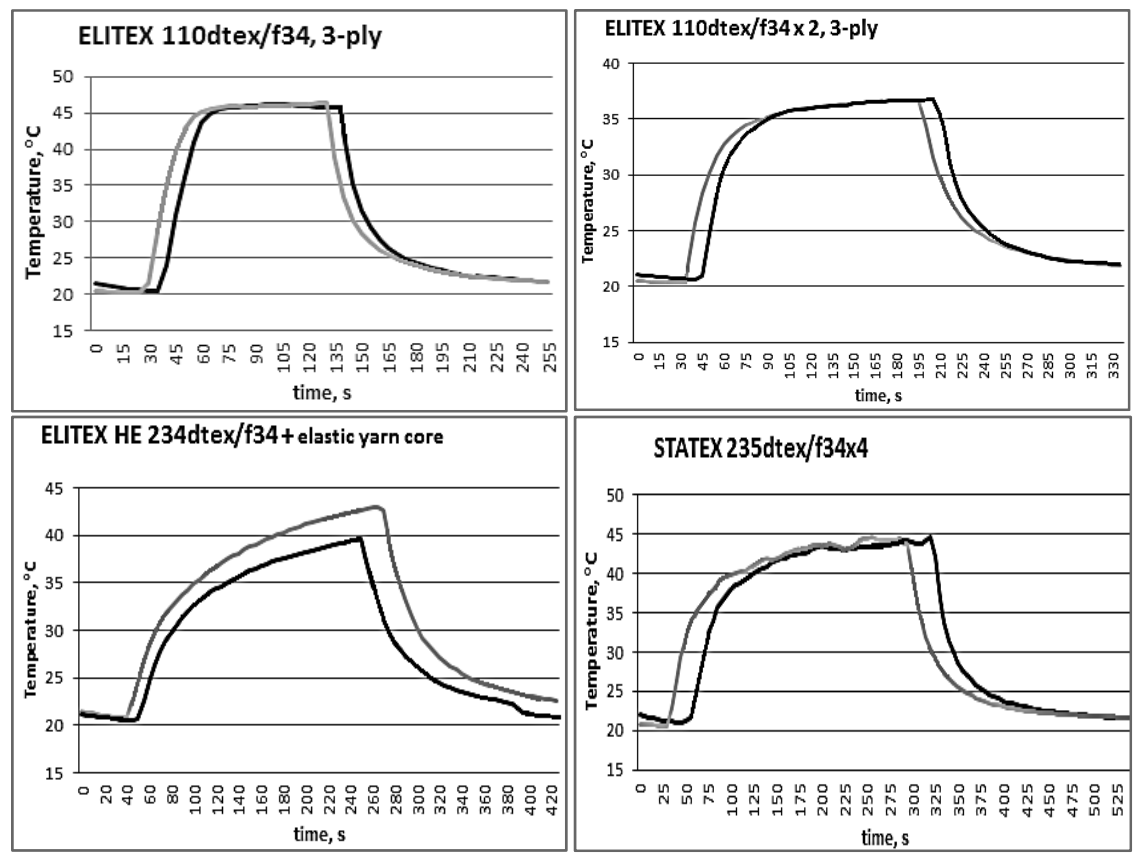

Figure 8: The warm-up temperatures and evenness measurements of knitted samples.

heating element with figural knitted conductive zones; the element heats up at a voltage of $1.75 \mathrm{~V}$ to a temperature of $35^{\circ} \mathrm{C}$ in less than one minute but by continuing the heating the temperature could reach $37^{\circ} \mathrm{C}$. Such temperature is sufficient to create comfortable warmth for the hands.

\subsection{Cyclic warm-up and cooling experiment}

The aim of the experiment is to find out how the maximum achievable temperature of the resistive heating element changes and how the temperature is saturated. The time of experiment is $1 \mathrm{~h} 40 \mathrm{~min}$; each heating period is 15 minutes, while cooling is 5 minutes. During this time, 5 heating and cooling cycles are performed; the optimal voltage chosen is $2 \mathrm{~V}$.

The experiment showed that heating and cooling of the knitted sample several times does not change significantly: after the 5 cycles the temperature rises to about $2^{\circ} \mathrm{C}(\sim 5 \%)$. The temperature reaches its maximum in the first cycle $\left(36.5^{\circ} \mathrm{C}\right)$ and in the last $\left(38.3^{\circ} \mathrm{C}\right)$. By heating the knitted sample for 15 minutes it can be observed that the temperature rises slowly and saturation varies insignificantly. The heating element performs the heating function without any significant changes in temperature over the time. 


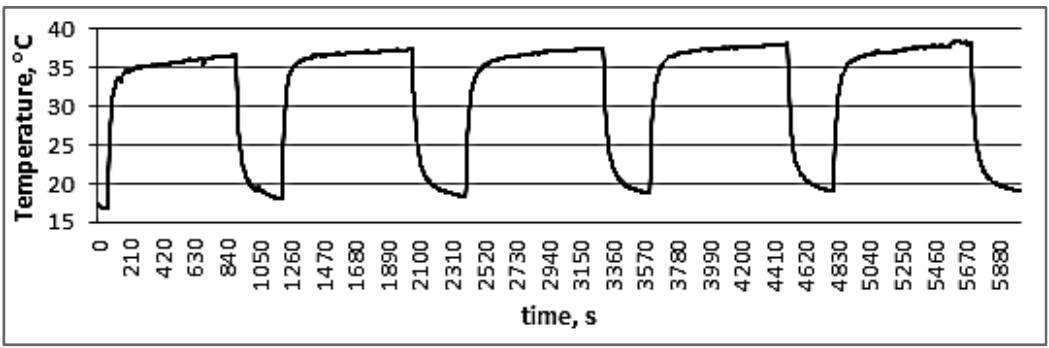

Figure 9: Cyclic warm-up and cooling experiment results.

For further work on the manufacturing of knitwear with a heating element the three-ply silver coated polyamide ELITEX 110dtex/f34x2-ply yarn will be used. By knitting the knitwear, a visually good-looking and technically feasible, with a relatively even warm-up character is obtained.

\section{Conclusions}

The most important results and conclusions of these experiments:

- Conductive yarns knitted into fabric depending on the yarn type increase or decrease their resistance in relation to initial resistance;

- Polyamide (80\%) and stainless steel $(20 \%)$ fibre spun yarn is more suitable for manufacture of stretch sensors because this type of yarn has a very high relative resistance change during the fabric tension;

- Technically unsuitable for knitting are stainless steel multifilament yarns because they are not sufficiently flexible and deform the knitting;

- Visually and technically more suitable yarns for knitting are multiplied silver coated polyamide ELITEX 110dtex/f34, ELITEX 110dtex/f34x2ply, SHIELDEX 235dtex/f34x4-ply and ELITEX HE 234dtex/34 with elastic yarn core;

- Evenness of warm-up is provided by three-ply silver coated polyamide yarns: ELITEX 110dtex/f34 and ELITEX 110dtex/f34 x 2-ply;

- The knitted heating element of three-ply ELITEX 110dtex/f34x2-ply yarn performs the heating functions without any significant changes in temperature over a long period of time.

The main criteria for the selection of yarns for manufacture of knitted resistive heating element are: low electrical resistance of yarns; low resistance changes during the elongation of the knitted heating element; temperature evenness of element for a long time and the suitability of yarns for knitting.

\section{Acknowledgements}

This work has been supported by the European Social Fund within the project "Support for the implementation of doctoral studies at Riga Technical University". 


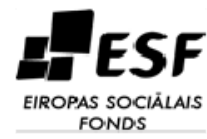
INVESTING IN YOUR FUTURE

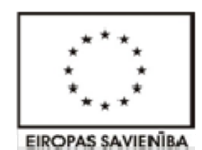

\section{References}

[1] Kirilovs E., Emsinšs J. Gaisa temperatūras ietekme uz darba produktivitāti birojā. RTU zinātniskie raksti, 9 (5), 88.-93. 1 pp, 2010.

[2] Zubieta-Calleja G., Paulev P. E. Textbook in Medical Physiology and Pathophysiology. University of Copenhagen: Copenhagen http://www.zuniv.net/physiology/book/chapter21.html

[3] Horrocks A. R., Anand S. C., Handbook of Technical Textiles. Woodhead Publishing: Cambridge, 95 p., 2000.

[4] Textilien und textile Produkte - Intelligente Textilien - Definitionen, Klassifizierung, Anwendungen und Normungsbedarf; Deutsche Fassung CEN/TR 16298:2011

[5] Kim Y., Kim H., Hoi-Jun Yoo, Electrical Characterization of ScreenPrinted Circuits on the Fabric. IEEE Transactions on Advanced Packaging, vol. 33, No. 1, pp. 196-205, February 2010.

[6] Locher I., Technologies for System-on-Textile Integration, Swiss Federal Institute of Technology: Zürich, p. 121, 2006.

[7] Tibtech Innovations http://www.tibtech.com

[8] Statex - World of Silver http://www.statex.biz

[9] Imbut http://www.imbut.de/

[10] Oghushi K., Hijiri M., Kitazawa Z., Fibrous heating element. United States Patent Application Publication. Nr. US 4983814, 1991.

[11] Tao X., Wearable Electronics and photonics. The Hong Kong Polytechnic University: Hong Kong, 205 p. 2005.

[12] Roell F., Electric heating element in knitted fabric. United States Patent Application Publication. Nr. US 5484983, 1996.

[13] Lee Sandbach D., Burkitt J., Walkington S.M., Crispin P.G., Knitted sensor. United States Patent Application Publication. Nr US 7377133, 2008.

[14] Frydrysiak M, Zięba J., Textronic Sensor for Monitoring Respiratory Rhythm. FIBRES \& TEXTILES in Eastern Europe, vol. 20, No. 2 (91) 75 p. 2012.

[15] Dias T., Hurley W., Monaragala R., Wijeyesiriwardana R., Development of Electrically Active Textiles. Advances in Science and Technology, vol. 60. pp. 74-84, September 2008

[16] Dias T., Smart Textiles - Adding Value to Sri Lankan Textiles. The Electronic Textiles Option, http://www.slideshare.net/SLINTEC/smarttextiles-adding-value-to-sri-lankan-textiles-the-electronic-textiles-optionhandout 